THE PEGASUS DRIVE: A NUCLEAR

ELECTRIC PROPULSION SYSTEM

FOR THE SPACE EXPLORATION INITIATIVE

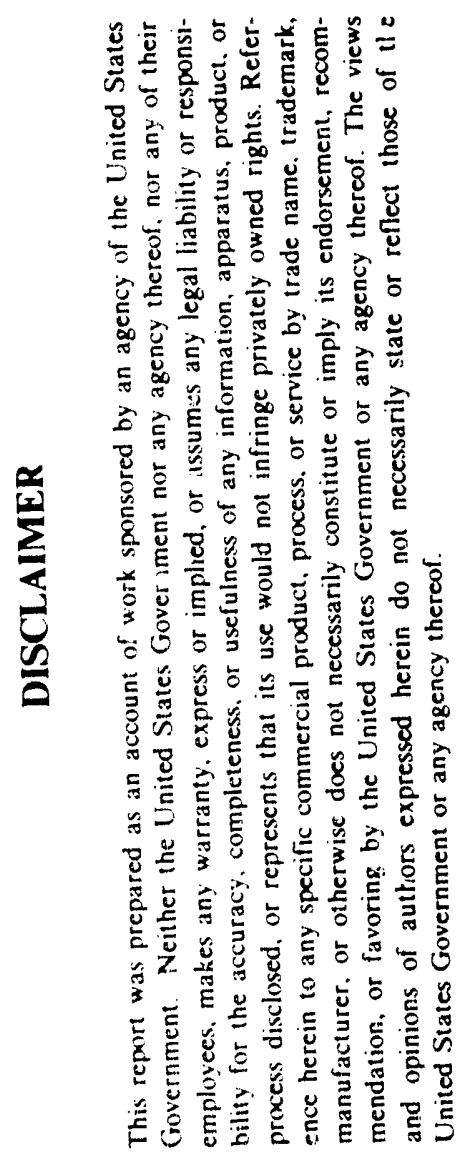

Edmund P. Coomes

Jeffery E. Dagle

October 1990

Presented at the

Eighth Symposium on

Space Nuclear Power Systems

Albuquerque, New Mexico

January 6-10, 1991

Work supported by

the U.S. Department of Energy

under Contract DE-A C.06-76RLO 1830

Pacific Northwest Laboratory

Richland, Washington 99352 
L.OG \#_152

Session \#-9

\title{
THE PEGASUS DRIVE: A NUCLEAR ELECTRIC PROPULSION SYSTEM FOR THE SPACE EXPLORATION INITIATIVE
}

\author{
Edmund P. Coomes and Jeffery E. Dagle \\ Pacific Northwest Laboratory \\ P.O. Box 999 M/S K5-21 \\ Richland, WA 99352 \\ (509) $375-2549$
}

CAMERA READY' MANUSCRIPT prepared for:

Eight Symposium

on Space Nuclear Power Systems

Albuquerque, New Mexico

6-10 January 1991

initial submission: 24 July 1990

Address ali correspondence to: Mr. Edmund P. Coomes

Work supported by

the U.S. Department of Energy

under Contract DE-AC06-76RLO 1830) 


\title{
THE PECASUS DRIVE: A NUCLEAR ELECTRIC PROPULSION SYSTEM F(OR THE SPACE EXPIORATION INITIATIVE
}

\author{
Edmund P. Coomes and Jeffery E. Dag!e \\ Pacific Northwest Laboratory \\ P.O. Box 999 M/S K5-21 \\ Richlind, WA 9y3.52 \\ (50) $375-2549$
}

\begin{abstract}
The advantages of using electric propulsion for propulsion are well-known in the aerospace community. The high specific impulse, lower propellant requirements, and lower system mass make it a very attractive propulsion option for the Space Exploration Initiative (SEI), especially for the transport of cargo. One such propulsion system is the PEGASUS Drive (Coomes et al. 1987). In its original configuration, the PEGASUS Drive consisted of a 10-MWe power source coupled to a $6-\mathrm{MW}$ magnetoplasmadyramic (MPD) thruster system. The PEGASUS Drive propelled a manned vehicle to Mars and back in 60) d day. By removing the crew and their associated suppor systems from the spacecraft and by incorporating technology acivances in reactor design and tieat rejection systems, a second generation PEGASUS Drive can be developed with an alpha less than two. Utilizing this propulsion system, a 400)-MT cargo vehicte, assembled and loaded in low Earth orbit (LEO), could deliver 262 MT of supplies and hardware to Mars 282 days after cscaping Earth orbit. Upon arrival at Mars the transport vehicle would place its cargo in the desired parking orbit around Mars and then proced to synchronous orbit above the desired landing sight. Using a laser transmitter, PECBASUS could provide 2-MWe on the surface to operate automated systems deployed earlier and then provide surface power to support crew activities after their arrival. The additional supplies and hardware, coupled with the arailability of megawatt levels of electric power on the Mars surface, would greatly enhance and even expand the mission options being considered under SEI.
\end{abstract}

\section{INTRODUCTION}

President Bush has chosen the expansion of human presence into the solar system as the focus of the American space program with the gual of landing of an American on Mars by the 50 th Anniversary of the Apollo 11 lunar landing. Developing a permanent presence in space requires a continual stepping outward from Earth in a logical progressive manner. If we seriously plan to go and to stay, then we must not only plan what we are to do and how we are to do it, we must address the logistic support infrastructure that will allow us to stay once we arrive. In this way, a permanent human presence in space can be sustained.

The Space Synthesis Group, under Retired General Thomas Stafford, is examining various architectures and technologies necessary to establish permanently manned bases on the moon and on Mars. A major concern is the logistic support these bases will require. To provide this support, higilly efficient cargo transport vehicles must be developed. Incorporating this need into integrated planning and taking advantage of hardware commonality, a multimegawatt nuclear electric cargo transport with a long-life power source coupled with a beam-power transmission system, looks very attractive as a dual function system by doubling as the surface energy source after its cargo transport function has been discharged (Bamberger 1990).

\section{Mission Analysis}

Any number of mission profiles may be devised for a manned Mars expedition, depending on the assumptions made concerning desired objectives and available technology. The split-sprint Mars mission scenario allows optimum transport of personnel and materials making this the mission of choice. An unmanned nuclear electric cargo vehicle, staged in LEO, is sent to Mars carrying all the necessary supplies and equipment needed to establish the Mars outpost. The manned mission, also staged in LEO, follows later using a chemical or nuclear-thermal propulsion system to transport Mars 
astronauts. Transport time is not a critical issue for the cargo transport craft; efficient mass transport is, whereas transport time is the critical issue for piloted spacecratt. The mass breakdown of a typical cargo mission is presented in Table 1.

The use of a separate nuclear electric-propelled cargo vehicle offers several unique mission options (Coomes and Bamberger 199()) not possible with a chemically-powered cargo vehicle. Taking advantage of the fuel savings offered by electric propulsion and with no need for the life support, habitat, or additional shielding systems required on a manned vehicle, the cargo transport vehicle could carry enough supplies in a single flight to support several manned flights to Mars. Being sent in advance, it could carry return or reserve fuel for the manned return flight. Coupling the nuclear electric power system to a beam-power transmission system, electric power can be supplied from geosynchronous Mars orbit (GMO) to the surface to support a broader range of activities. Automated systems deployed from the cargo vehicle or left operating when the crew returns to Earth could convert raw materials on the Mars surface into usahle form, which would then be available to the inanned flights that follow. Finally, a backup return vehicle wolld be available should the primary manned space craft become disabled. The crew could reconfigure the two spacecraft (already in orbit around Mars) and use the propulsion system of the cargo vehicle to propel them home. Figure 1 shows the 282 day mission trajectory for the outbound cargo vehicle and the 345 day return leg for the reconfigured backup piloted vehicle after a 3() day stay at Mars.

TABLE 1. Mars Cargo Vehicle Mass Summary

\begin{tabular}{|c|c|c|c|c|c|}
\hline \multicolumn{2}{|c|}{ PROPULSION COMPONENTS } & $\operatorname{MASS}(\mathrm{kg})$ & \multicolumn{2}{|c|}{ POWER SYSTEM } & MASS $(k g)$ \\
\hline \multicolumn{2}{|c|}{ MPD Thruster Assembly } & 700 & \multicolumn{2}{|c|}{ Reactor } & 5,340 \\
\hline \multicolumn{2}{|c|}{ Engine Control Assembly } & 50 & \multicolumn{2}{|c|}{ UN Fuel } & \\
\hline \multicolumn{2}{|c|}{ trigh Current Buss } & 817 & \multicolumn{2}{|c|}{ Molybienum } & \\
\hline Rectifier Assembly & & 200 & \multicolumn{2}{|c|}{ Vesscl \& Reflector 1,648} & \\
\hline \multicolumn{2}{|c|}{ Transformer Assembly } & 1,911 & \multicolumn{2}{|c|}{ Support Structure } & 1,359 \\
\hline \multicolumn{2}{|c|}{ AC Buss Components } & 69 & \multicolumn{2}{|c|}{ Potassium Inventory } & 9() 7 \\
\hline \multicolumn{2}{|c|}{ Thermal Control Systems } & 156 & \multicolumn{2}{|c|}{ Shadow Shiclil } & 5,105 \\
\hline \multicolumn{2}{|c|}{ Subsystem Totial } & 3,897 & \multicolumn{2}{|c|}{ Turbines \& Alternators } & 4,334 \\
\hline \multicolumn{2}{|c|}{ Contingency Mass (10\%) } & 390 & \multicolumn{2}{|c|}{ Fabric Heal Pipe Radiator } & 1,698 \\
\hline \multicolumn{2}{|c|}{ Structural Mass $(? 0 \%)$} & 857 & \multicolumn{2}{|c|}{ Auxiliary cooling } & 907 \\
\hline \multirow[t]{11}{*}{ Propulsion $s \quad \ldots$ Total } & & 5,150 & \multicolumn{2}{|c|}{ Power System Total } & \multirow[t]{10}{*}{$19,6.50$} \\
\hline & \multicolumn{3}{|c|}{ SPACECRAFT COMPONENTS } & MASS (kg) & \\
\hline & \multicolumn{3}{|c|}{ Supplies, Lander, Rover, elc. } & $168,(000$ & \\
\hline & \multicolumn{2}{|c|}{ Power \& Propulion } & & $24,8()()$ & \\
\hline & \multicolumn{2}{|c|}{ Power Transmilter } & & $25,0(0)$ & \\
\hline & \multicolumn{2}{|c|}{ Propellant (Oubsurds) } & & $55,(0)(0)$ & \\
\hline & \multicolumn{2}{|c|}{ Propellant (Crew relun } & & $66,()(0)$ & \\
\hline & \multicolumn{2}{|c|}{ Propellant Tankage } & & 18,000 & \\
\hline & \multicolumn{3}{|c|}{ Navigation, Command, \& Control } & $13,2()()$ & \\
\hline & \multicolumn{3}{|c|}{ Suructure \& Miscellancous } & 30,000 & \\
\hline & Total Sp & aft Mass & & 400,000 & \\
\hline
\end{tabular}




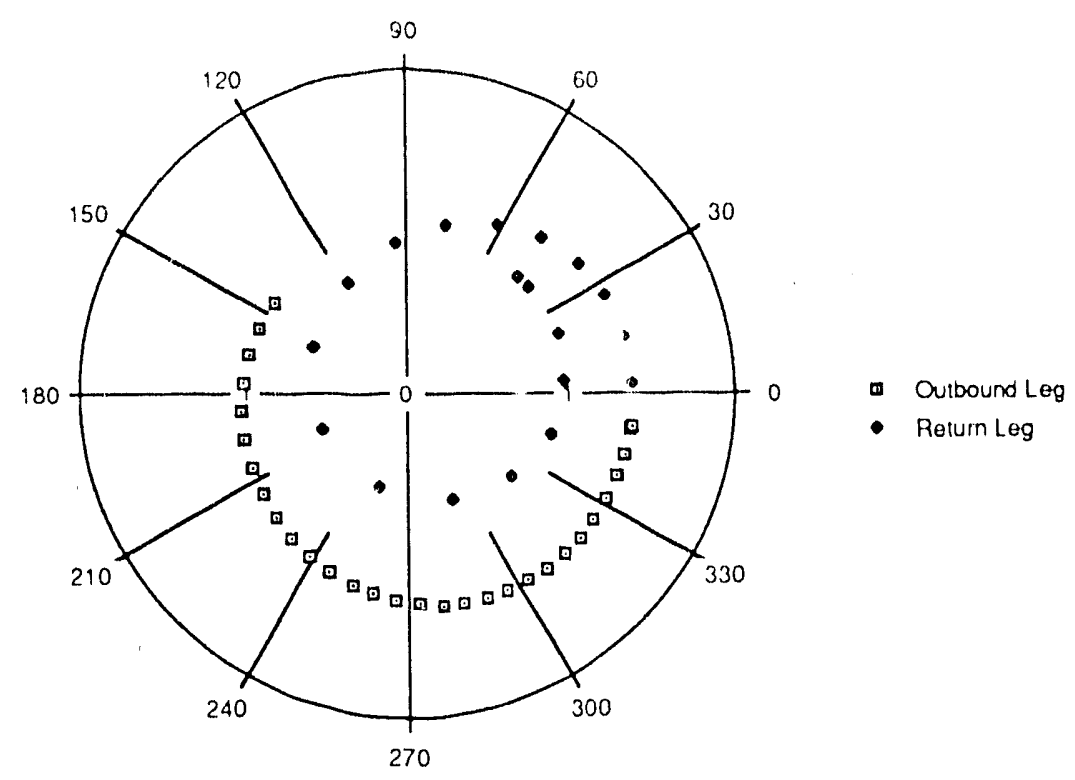

FIGURE 1. Typical PEGASUS Drive Cargo and Emergency Return Vehicle Trajectories

\section{Propulsion System}

Electric propulsion systems have not been seriously considered for use with large spacecraft due to the lack of a suitable electric power source to drive them. However, recent efforts to develop megawattclass space power sources show such systems to be technologically feasible, and a multimegawatt lightweight nuclear electric propulsion system would enable missions of almost any conceivable duration and scope. A 10-MWe Mars cargo transport vehicle is a very viable system. The MPD thruster coupled with a nuclear electric power plant provides the most attractive electric propulsion system. The propulsion system itself is simple, compact, and extremely rugged. Such a propulsion system is described in the following sections.

\section{MPD Thruster Sysiem}

The MPD thruster system is composed of thrusters, propellant tanks, power conditioning, and thermal control subsystems. The thruster assembly consists of seven MPD engines that are used one at a time. All seven engines are connected in parallel to a high current buss, but each has a separate propellant valve and contactor for the cathode current feed. Performance development may change the electrode shape somewnat, but the overall dimensions of a multimegawatt thruster will remain about the same (King and Vondra 1984). Each engine is assumed to have a center-body cathode $3 \mathrm{~cm}$ in diameter and $10 \mathrm{~cm}$ long, with an anode about $12 \mathrm{~cm}$ inside diameter and of a comparable length. With the present understanding of cathode physics, thruster lifetime (which is limited by the cathode) is about 2,000 hours. The most massive part of the MPD engine is the anode heat removal system, which must remove approximately $300 \mathrm{~kW}$. An allowance of $700 \mathrm{~kg}$ is made for the assembly of seven engines, contactors, and thermal control.

Three phase $\mathrm{AC}$ is fed through transformers and rectifiers to the thruster. Power control and regulation is confined to adjustments of the $\mathrm{AC}$ output from the alternator. A high voltage buss runs from near the turboalternator past the reactor shield to the transformer. To enhance reliability, the rectifier is designed to use 3,000 amperes radiation hardened diodes derated to 1,500 amperes. Eight diodes are connected in parallel in each of the units for full wave rectification of three phase AC. A contingency of $10 \%$ of the system mass is included, and $20 \%$ on top of that added for structure. The electrical system is $87 \%$ efficient while the MPD thruster is assumed to have a $50 \%$ conversion efficiency. A summary of the mass breakdown of the thruster system is provided in Table 1. 


\section{ELECTRIC POWFR SOURCE}

PEGASUS, the proposed power source for the MPD thruster system, is a 10 -MWe boiling liquidmetal reactor power system. The system employ's a direct rankine power cycle and is designed to meet the power requirements for a 10-MVe electric propulsion system and the operational needs of the power system and spacecraft itself. The power system is comprised of tive major subsystems or components: a cermet fueled, boiling liquid metal fast reactor; a shadow shield: two radial ilow Ljungstrom turbines with four superconducting alternators for power conversion; a power conditioning subsystem; and a heat rejection/thermal control subsystem. Table 1 includes at mass breatidown of the power subsystem.

\section{Reactor Subsystem}

The reactor selected for the PEGASUS sy'stem is a fast reactor using a boiling alkali metal coolant and cermet fuel. The cermet fuel is composed of a refractory-metal matrix, such as tungsten, with $93 \%$ enriched Uranium Nitride as the fuel material. A cermet fuel was selected because of its superior thermal characteristics and its capability to withstand the high stresses imposed by enhanced fission gas release and fuel swelling. A strong, relatively ductile metal matrix with a high thermal conductivity is well suited to the needs of a reactor where rapid power swings are necessary to meet varying power demands. Also the enclosed coolant channel configuration eliminates cross flow instabilities that occur during boiling in open lattice cores.

\section{Reactor Design}

A reactor system designed to operate in space should take maximum advantage of the space environment rather than be a simple extrapolation of terrestrial reactor systems. The split core radial-inflow reactor core (Coomes 1988) does just that. Coolant flows radially inward through the core where it is boiled, exiting the fueled region as a vapor, and entering a central outlet plenum. The outlet plenum along the core central axis feeds two outlet manifolds located at either end of the reactor. The core is composed of monolithic fuel blocks with internal coolant channels and are held in concentric rings around a center plenum. These rings are stacked axially to produce a cylindrical core. Each axial level of the fuel is retained in its proper location in the core by grooved spacer discs that sandwich the rings of fuel blocks. These spacer discs accommodate thermal expansion anci possible fuel swelling. The radial inward flow and the corresponding increase of specific volume ot the potassium as boiling occurs, results in high vapor velocities, 25 to $40 \%$ of sonic, through the firal fuel rings. This makes it possible to maintain adequate heat transfer under all operating conditions even as severe as a sudden order of magnitude increase in power. Since this is a boiling system, the core operates with a uniform core temperature throughout most of its volume. In addition, by removing the inner most ring of UN/Moly alloy cermet fuel and replacing it with a UN/Tungsten cermet, it is possible to operate this core design with 25 to $50^{\circ} \mathrm{K}$ of super-heat, eliminating the need for a moisture separation system at the core outlet.

\section{Un-Cermet Fuel}

The UN/Moly alloy cermet fuel was selected because of the high fissile density of UN (30\% greater than $\mathrm{UO}_{2}$ ), the high temperature strength of the molybdenum alloy, and the ruggedness of cermet. The use of cermet fuel blocks with internal coolant flow channels, the use of UN in a matrix of refractory metal alloy of molybdenum, hafnium, and rhenium, and the arrangement of these fuel blocks in a radial-inflow geometry provides unique characteristics (Bamer et al., 1986) that are in direct contrast to typical clad fuel-pin core designs, even those using UN as the fuel.

A cermet fuel has a much greater resistance to thermal shock and stress (imposed by fission gas release) caused by sudden transients or cyclic operation over the life of the core and an ability for extended burnup providing long mission life. The strong, relatively ductile, high-thermally-conductive metal matrix and rugged configuration of the fuel block provides greater reliability than any other fuel material or fuel form. The absence of interconnecting porosity between the individual particles of UN and using $80 \%$ dense UN particles, increase the ability to retain fission products, thus minimizing fuel swelling over the life of the core. The combination of high thermal conductivity and thin fuel webs 
between coolant channels allows high surface temperatures $(1.50) \mathrm{K}$ ) while maintaining relatively moderate peat fuel temperatures $\left.(16.5)^{\circ} \mathrm{K}\right)$. The fuel composition of approximately $25 \%$ average UN loading in a Mo-Re-Hi alloy matrix results in a configuration that has a negative reactivity worth for any water entering the core and central cavity. This eliminates the concern over water immersion that could result from a hypothetical launch abort accident. This negative worth of water is due to the poisoning effect the Re and Hf would have because of the softer spectrum that results from the addition of water to the core.

\section{Reactor Control}

Reactor control for this core configuration is accomplished by two independent control systems. One system is for coarse reactivity control to accommociate burnup and the second system provides operational control for load following. Burnup control is accomplished by adjusting the separation distance of the two core halves with the four rod drives connected to the movable core half. Split core control uses the change in core geometry to produce a sub-critical core configuration and thus controls reactor criticality directly. This provides a very rapid shutdown that is independent of delayed neutron effects and provides a much greater prompt drop effect. The operational control is accomplished by movable reflector segments located outside the pressure vessel and employs neutron leakage from the periphery of the core as the primary mechanism for operational control. Operational control system consists of 16 movable beryllium oxide reflector segments that are connected to individual control drive mechanisms located outside of the reactor containment can. This makes it possible for reflector segments to be withdrawn up to $25 \mathrm{~cm}$ from the reactor vessel.

\section{Reactor Shielding Subsystem}

The PEGASUS system incorporates a shadow shield to reduce radiation from the reactor to safe levels for equipment and cargo during full-power operation. The shield is a composite material of depleted $\mathrm{LiH}, \mathrm{W}$, and $\mathrm{LiH}$ (Barattino 1985). To maintain the physical integrity of the shield, it is cooled by the reactor inlet coolant.

\section{Power Conversion Slibsystem}

Power conversion is accomplished by three turboalternators. The turbine designs incorporate a multi-stage radial out-flow design developed by Berger Ljungstrom (Ljungstrom 1949) in 1910. This turbine design is a very compact high power density turbine. The turbines are radial out-flow configurations designed to operate with an inlet pressure of $1.5 \mathrm{MPa}$ and an exit quality of $70 \%$. Superconducting alternators are chosen to develop the electrica! power because of their high power-toweight ratio. Each superconducting alternator is expected to operate at $1500 \mathrm{~Hz}$ and 10 to $20 \mathrm{kva}$, and be capable of providing a continuous electric power output of 5 r.egawatts. (Doage et al. 1987). The overall power conversion subsystem is expected to have a specific weight on the order of $0.5 \mathrm{~kg} / \mathrm{kW}$ and an efficiency of $98 \%$.

\section{Heat Rejection and Thermal Control Subsystem}

Heat rejection for the PEGASUS is accomplished by means of high and low temperature heat rejection subsystems. The high temperature subsystem handles waste heat rejection from the turbines. The low $t \in m$ merature subsystem takes care of waste heat from the alternator and other components requiring cooling. The high temperature heat rejection system consists of three ceramic fabric heat-pipe radiators, associated pumps, piping, and structure. The radiator is sized to reject $21.5 \mathrm{MW}$ of waste heat from the system during full-power operation.

The low-temperature heat rejection sy'stem consists of an auxiliary cooling system designed to reject waste heat produced within the alternator and other equipment operating at much lower temperatures. The auxiliary cooling system has its own working fluid, pumps, and radiator. This system utilizes helium as its working fluid and is composed of a Sterling cycle cryogenic cooler, an auxiliary chiller, a low-temperature radiator, and associated pumps and piping. The cryogenic cooler removes heat from 
the liquid helium and transfers this heat to the auxiliary coolant in the chiller. A closed loop system? is used to pump this coolant through the auxiliary cooling radiator located around the perimeter of the main radiator. Before returning to the chiller, this coolant is used to cool pumps and other components.

\section{CONCLUSIONS}

Cargo transport has never been a time critical activity. This makes a nuclear electric cargo vehicle the ideal space craft to carry the equipment and supplies necessary to sustain human expansion into the solar system. Utilizing new and improved technologies developed under the Department of Energy's Multi Megawatt Program, an upgraded PEGASUS Drive propulsion system has the ability to meet the needs of a Mars cargo transport vehicle. Nuclear electric pro." 'sion, when coupled with a beam-power transmission, provides significant mission enhancement opening new mission options not possible with other propulsion systems.

\section{Acknowledgments}

This work was performed at the Pacific Northwest Laboratory operated for the U.S. Department of Energy under Contract DE-ACO6-76RLO 1830) by Battelle Memorial Institute.

\section{References}

Bamberger, J.A. (1990) "A New Method for Power Generation and Distribution in Outer Space," in Proceedings: Seventh Symposium on Space Nuclear Power Systems, M. S. El-Genk and M. D. Hoover, eds., Vol. 1, pp 387-392, Institute for Space Nuclear Power Studies Albuquerqu ‘. NM.

Earattino, W. J. (1985) Thermal and Stress Analysis of Radiation Shield for Space Reac ors, Ph.D Dissertation, Department of Chemical and Nuclear Engineering, University of Neu Mexico, Albuquerque, New Mexico, May 1985.

Barner, J. O., E. P. Coomes, R. E. Williford and L. A. Neimark (1986) "Cermet Fuels for Space Power Systems," in Proceedings: Third Symposium on Space Nuclear Power Systems, M. S. El-Genk and M. D. Hoover, eds., pp RF-10.1-10.4, Institute for Space Nuclear Power Studies Albuquerque, NM.

Coomes, E.P. and J.A. Bamberger (1990) "Applications and Space Mission Enhancements Made Possible with a Nuclear-Driven Beam-Power Sy'stem," in Proceedings: Seventh Symposium on Space Nuclear Power Systems, M.S. El-Genk and M.D. Hoover, eds., Vol. 1, pp 16-20, Institute for Spact Nuclear Power Studies, Albuquerque, NM.

Coomes, E.P. (1988) "A High Power Density Radial-In-Flow Reactor Split-Core Design for Space Power Systems," in Proceedings: Fifth Symposium nn Space Nuclear Power Systems, M. S. ElGenk and M. D. Hoover, eds., pp 397-4()1, Institute for Space Nuclear Power Studies Albuquerque, NM.

Coomes, E.P.,J.M. Cuta, B.J. Webb, and D.Q. King (1987) "The PEGASUS Drive: A Multimegawatt Nuclear Electric Propulsion System," in Space Nuclear Puwer System.s, M. S. El-Genk and M. D. Hoover, eds., Orbit Book Co., Malabar, Florida,Vol. V, pp 365-373.

Dodge, R.E., E.P. Coomes, J.L. Kirtley, and S.J. McCabe (1987) "Design of a Superconducting Alternator for Space-Based Power Generation," in Proceedings: Fourth Svmposium on Space Nuclear Power Svstems, M. S. El-Genk and M. D. Hoover, eds., Institute for Space Nuclear Power Studies Albuquerque, NM.

King, D. Q. and R. J. Vondra (1984) "Development Status and Projected Power Requirements of MPD Thrusters," preser. ed at the Space Nuclear Propulsion Conference, Los Alamos, NM, December 1984.

Ljungstrom, B. (1949) "The Development of the Ljungstrom Steam Turbine and Air Preheater", in Proc. International Mechanical Engineering Conference, April 1949, Vol. 160, pp. 262-265. 

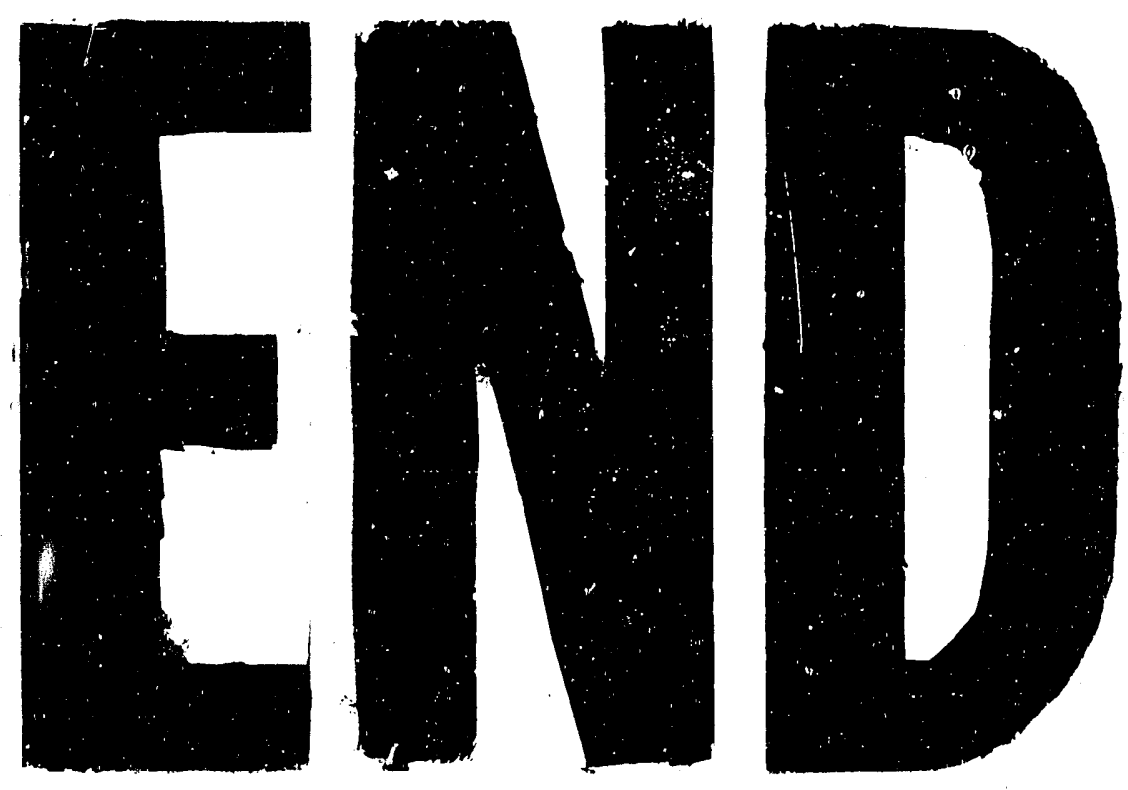

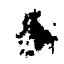
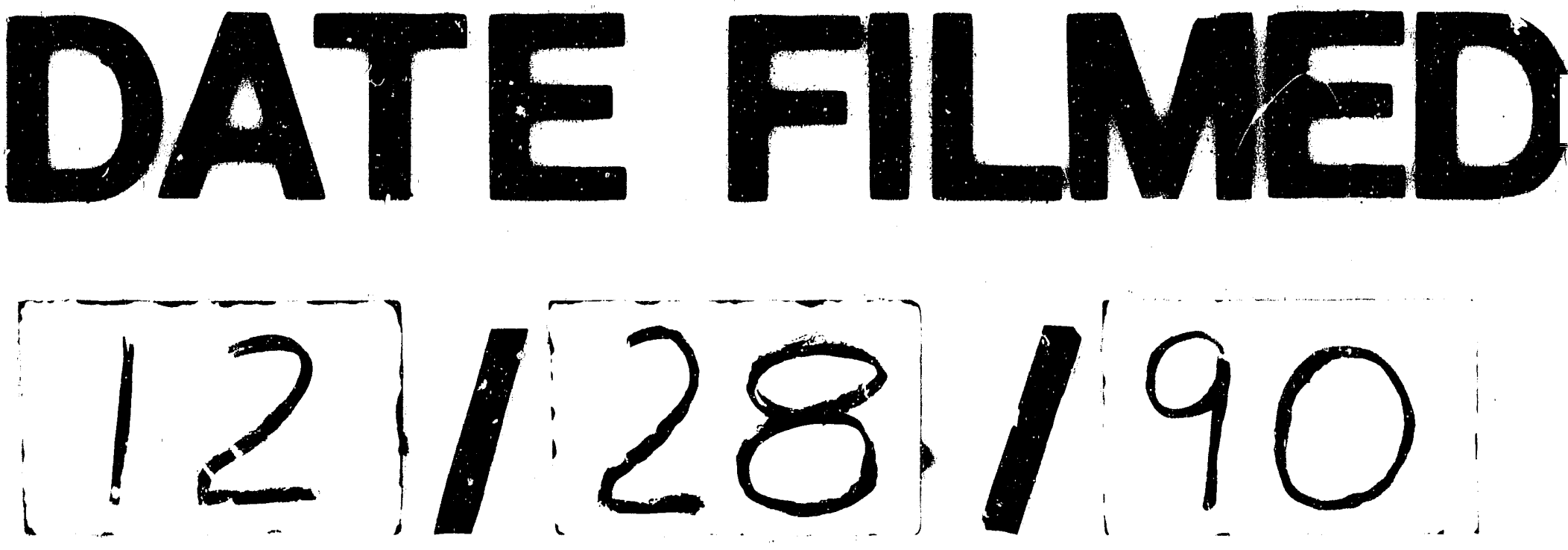
